\title{
HIV/AIDS, LAW AND ETHICS: A BRIEF ANALYSIS OF SOME PERTINENT ISSUES
}

\author{
Elsabé Klinck \\ Director: Research, Compliance and Counselling, Foundation for Professional Development
}

\section{LAW AND ETHICS}

In no other field is the role of law and ethics as crucial as in the field of HIVIAIDS. Health care professionals are in a unique situation, as both legal and ethical rules apply to a single HIV-related situation faced by them. Legal and ethical rules sometimes overlap, but sometimes differ. The South African Constitution and its Bill of Rights complicates matters further in that it is the highest law, and even ethical rules and rulings may be challenged as being justifiable limitations to human rights principles.

Perhaps the most well-known rule of medical ethics is 'do no harm.' In South Africa the Health Professions Council has issued a variety of ethical rules and its professional boards have made various rulings further concretising the application of these ethical rules. This body of rules and rulings is supplemented by policy statements, such as the Guidelines for the Management of Patients with HIV Infection or AIDS and the Policy Document on Undesirable Business Practices, which also contains various provisions on managed care.

\section{HUMAN RIGHTS AND RESPONSIBILITIES}

The following human rights play an important role for people living with HIV:

- The right to (substantive) equality and nondiscrimination

- The right to privacy (confidentiality)

- The right to human dignity

- The right to security of the person (to make informed decision about one's body)

- The rights of access to health care and access to social security (welfare and insurance)

The right of access to information.

These rights do, however, also entail responsibilities. The right of access to health care implies the responsibility to take care of one's own health and to follow the instructions of one's practitioner; the right of access to social security in the form of health care funding implies the duty not to abuse benefits awarded by schemes.

\section{COUNSELLING AND INFORMED CONSENT}

Pre- and post-test counselling form an integral part of the process of obtaining informed consent from a patient. Not only does it show respect for the physical integrity and human dignity of the patient, it prepares the patient for the potential outcome of a test and issues that may arise from such an outcome.

A typical pre-test counselling session could include:

What the test is

How it is done

- All advantages and disadvantages of undertaking a test and knowing the results

- What a positive result means

What a negative result means

- The chances and implications of an incorrect result

- Appropriate support structures available, etc.

Concerns on funding of further health care may also be high on a patient's list of questions and should be addressed. Some of the issues raised during such sessions may indeed necessitate legal support. Practitioners may find it useful to have a list of support organisations and telephone numbers available for patients.

Post-test counselling should revisit the above points, and, in general, serve to facilitate patients' decision-making on future health care. The health care options and effects of each need to be discussed, as well as the ongoing and longer-term health care planning of the patient.

The National Health Act of 2003, which is not yet in force, sets the following prerequisites for informed consent:

- The range of diagnostic procedures and treatment options available to the patient

- The benefits, risks, costs and consequences generally associated with each option

- The right to refuse services, but also the implications, risks and obligations accompanying such refusal.

It also sets a whole new requirement in that where health services have been provided without consent, the provincial head of a health department must be informed of such fact within 47 hours. 
The requirement to obtain a patient's informed consent may be disposed of where a law so authorises or a court so orders. The National Health Act of 2003 also authorises treatment without consent where failure to treat the patient will result in a serious risk to public health. This clause may, albeit unjustifiably, be used in the HIV setting. Another contentious section involves circumstances in which it would be justifiable for a professional not to discuss a patient's health status with him or her, i.e. if there is substantial evidence that the disclosure would be contrary to the best interests of the user. As these sections may indeed limit the rights of patients, both should be narrowly construed and applied.

Although not mandatory, it is advisable to obtain written consent. A typical consent form should include that the patient received the required information (listed in the document) and has understood such information, and that the patient provides his or her informed consent for the test and/or to be informed of the results thereof and/or treatment. If the form refers to treatment, the patient has to declare that s/he understands the requirements set in terms of compliance and the effects of the failure to comply. Patients may also be requested to agree to the anonymous use of their data for purposes of practice profiling, epidemiological data or files-based research projects.

\section{CONTENTIOUS ISSUES}

Needle-stick injuries remain a bone of contention. However, in the absence of legislation authorising testing without consent, if is submitted that the patient's consent should be obtained, failing which post-exposure prophylaxis (PEP) should be commenced.

Testing in the pre-operative setting should serve to protect the health care, and especially the postoperative health care decisions, of the patient. Testing solely to 'protect other health care workers' may result in a false sense of security and a violation of ethics (acting in the best interest of the patient) and human rights (obtaining informed consent).

A third contentious area is where patients have been tested accidentally. It is advisable to discuss the circumstances with the patient and explain the importance of knowing one's HIV status.

Patients who are unwilling to undergo testing also present a particular difficulty to practitioners, especially where a practitioner strongly suspects that the patient is HIVpositive. The clinical signs of HIV may be explained to the patient, but it may be advisable to get to the root of this unwillingness, if necessary by means of counselling.

Other unresolved areas include disclosing HIV status for a known sex partner, accessing medical scheme benefits and insurance products, and access to health care in the public sector.

The well-known nevirapine case provides us with a good guideline on the issue of access to treatment in that the Constitutional Court ruled that if a medical practitioner is of the opinion that nevirapine is clinically indicated, it should be provided to the patient. Patients living with HIV and whose rights are in jeopardy may be greatly assisted if practitioners fight to retain their clinical independence.

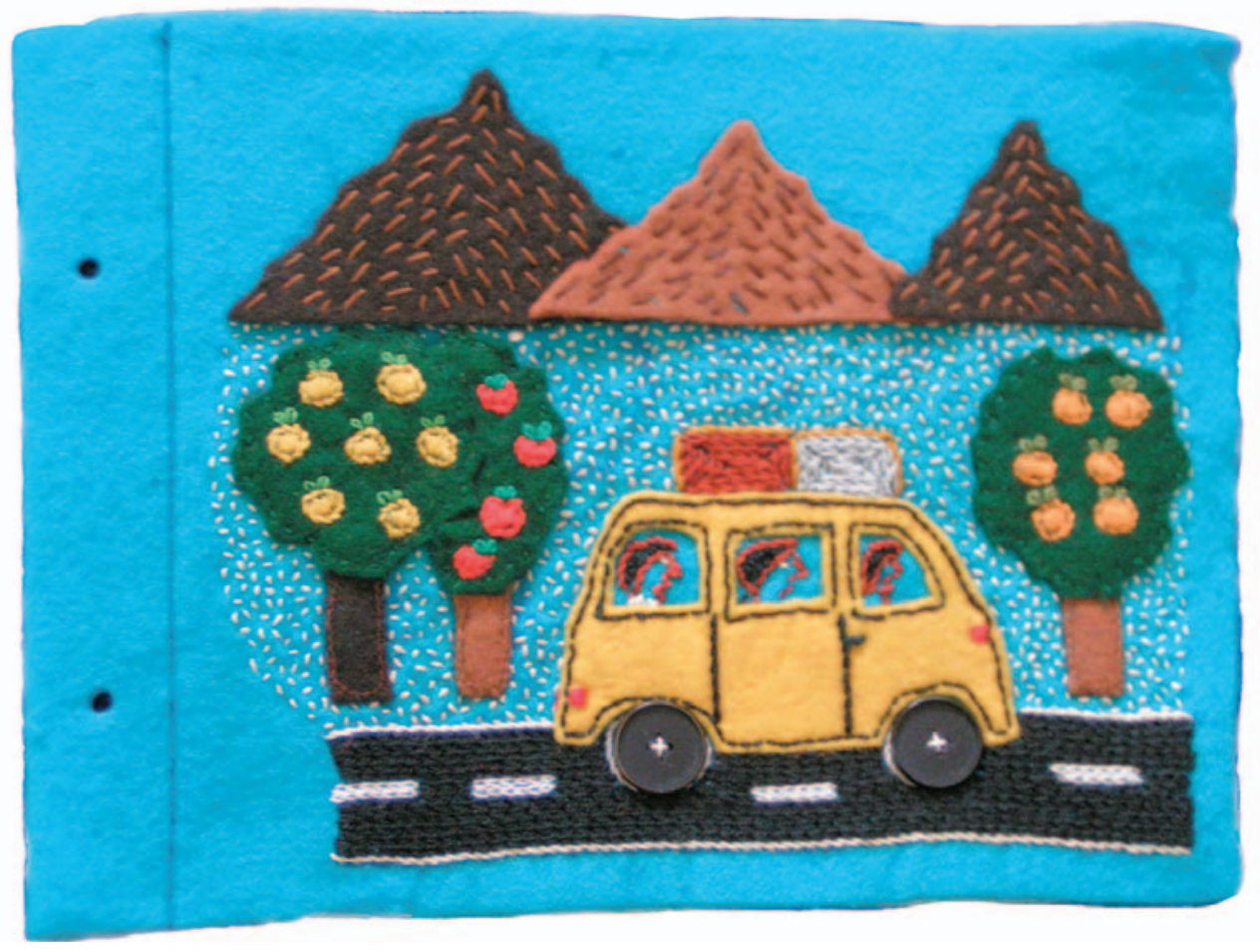

